\section{Efficient synthesis of plate-like crystalline hydrated tungsten trioxide thin films with highly improved electrochromic performance $\dagger$}

\author{
Zhihui Jiao, ${ }^{a}$ Xiu Wang, ${ }^{b}$ Jinmin Wang, ${ }^{a}$ Lin Ke ${ }^{c}$ Hilmi Volkan Demir ${ }^{d e}$ Tien Wei Koh ${ }^{a}$ \\ and Xiao Wei Sun*af
}

Received 12th September 2011, Accepted 4th November 2011

DOI: $10.1039 / \mathrm{clcc15629b}$

Plate-like hydrated tungsten trioxide $\left(3 \mathrm{WO}_{3} \cdot \mathrm{H}_{2} \mathrm{O}\right)$ films were grown on a fluorine doped tin oxide (FTO) coated transparent conductive substrate via an efficient, facile and template-free hydrothermal method. The film exhibited a fast coloration/bleaching response $\left(t_{\mathrm{c} 90 \%}=4.3 \mathrm{~s}\right.$ and $\left.t_{\mathrm{b} 90 \%}=1.4 \mathrm{~s}\right)$ and a high coloration efficiency $\left(112.7 \mathrm{~cm}^{2} \mathrm{C}^{-1}\right)$, which were probably due to a large surface area.

In recent years, nanostructured materials have attracted much attention due to their large surface area and size dependent properties, which offer great advantages in various applications. Tungsten trioxide $\left(\mathrm{WO}_{3}\right)$, a well-known transition metal oxide, has evoked wide interest owing to its distinctive physical and chemical properties that make it suitable for extensive applications in electrochromic (EC) devices, ${ }^{1-13}$ gas sensors, ${ }^{14,15}$ photocatalytic systems ${ }^{16}$ and photoelectrochemical devices. ${ }^{17-19}$ EC devices made of $\mathrm{WO}_{3}$ films have been intensively studied during the last few years, because of their promising applications in energy-efficient windows that can control the solar light transmission indoors through reversible color changes, contributing therefore not only significantly to energy saving in buildings (as a result of curtailing

${ }^{a}$ School of Electrical and Electronic Engineering, Nanyang

Technological University, Nanyang Avenue, Singapore 639798,

Singapore.E-mail: exwsun@ntu.edu.sg, jiao0013@e.ntu.edu.sg; Fax: + 65-67933318; Tel: + 65-67905369

${ }^{b}$ School of Materials Science and Engineering, Nanyang

Technological University, Nanyang Avenue, Singapore 639798, Singapore

${ }^{c}$ Institute of Material Research and Engineering, $A^{*} S T A R$

(Agency for Science, Technology and Research), Research Link, Singapore 117602, Singapore

${ }^{d}$ Department of Electrical and Electronics Engineering, Department of Physics, UNAM-Institute of Materials Science and Nanotechnology, Bilkent University, Bilkent, Ankara 06800, Turkey

${ }^{e}$ School of Electrical and Electronic Engineering, School of Physical and Mathematical Sciences, Nanyang Technological University, Nanyang Avenue, Singapore 639798, Singapore

${ }^{f}$ Department of Applied Physics, College of Science, and Tianjin Key Laboratory of Low-Dimensional Functional Material Physics and Fabrication Technology, Tianjin University, Tianjin 300072, China

$\dagger$ Electronic supplementary information (ESI) available: Experimental details, the Raman and XPS spectra of the nanoplate film, a schematic illustration of the film formation process, $\mathrm{CV}$ curves of the film grown with and without $\mathrm{Na}_{2} \mathrm{SO}_{4}$, the UV-vis transmittance spectra and photographs of the EC device, switching properties of the nanoplate film under $\pm 0.1 \mathrm{~V}$ and $\pm 0.2 \mathrm{~V}$ and the summary of the electrochromic characteristic parameters of $\mathrm{WO}_{3}$ films fabricated by various methods. See DOI: $10.1039 / \mathrm{clcc} 15629 \mathrm{~b}$

of air conditioning) but also comfortable esthetics. ${ }^{20} \mathrm{WO}_{3}$ can display colorless and blue color by alternately applying suitable positive and negative electrical voltages, which induces the cations such as proton $\left(\mathrm{H}^{+}\right)$and lithium $\left(\mathrm{Li}^{+}\right)$to insert into or extract from the host material at the same time. Compared with the amorphous structure, crystalline $\mathrm{WO}_{3}$ demonstrates better durability due to the denser structure and slower dissolution rate in electrolytes, especially in acidic ones where a faster ion diffusion kinetics can be achieved than in the $\mathrm{Li}^{+}$system. ${ }^{8,21}$ Nanostructured crystalline $\mathrm{WO}_{3}$ with a large specific area and a porous structure is expected to significantly improve the coloration/bleaching response and coloration efficiency by reducing the ion diffusion path length and resistance. ${ }^{8,12}$ In this work, we report the development of plate-like nanostructured $\mathrm{WO}_{3}$ (hydrate) films via an efficient and facile crystal-seed-assisted hydrothermal approach with sodium sulfate $\left(\mathrm{Na}_{2} \mathrm{SO}_{4}\right)$ used as the capping agent. The film shows a fast switching response $\left(t_{\mathrm{c} 90 \%}=4.3 \mathrm{~s}\right.$ and $\left.t_{\mathrm{b} 90 \%}=1.4 \mathrm{~s}\right)$ and a highly improved coloration efficiency $\left(112.7 \mathrm{~cm}^{2} \mathrm{C}^{-1}\right)$.

In a typical procedure, a crystal-seed-coated FTO substrate and a peroxopolytungstic acid precursor containing $\mathrm{Na}_{2} \mathrm{SO}_{4}$ were hydrothermally treated at $180{ }^{\circ} \mathrm{C}$ for $2 \mathrm{~h}$ (see the experimental section in $\mathrm{ESI} \dagger$ ). Fig. 1a shows the X-ray powder diffraction (XRD) patterns of the bare FTO substrate and the as-prepared thin films grown with and without $\mathrm{Na}_{2} \mathrm{SO}_{4}$. The XRD pattern of the substrate can be clearly indexed to tin oxide (JCPDF 70-4176). The hydrothermally grown films have the same crystalline structure since all diffraction peaks appear at the same position, and no other impurity peaks are observed. The sharp peaks indicate the good crystalline quality of the as-fabricated films. All peaks can be well indexed to the orthorhombic phase of
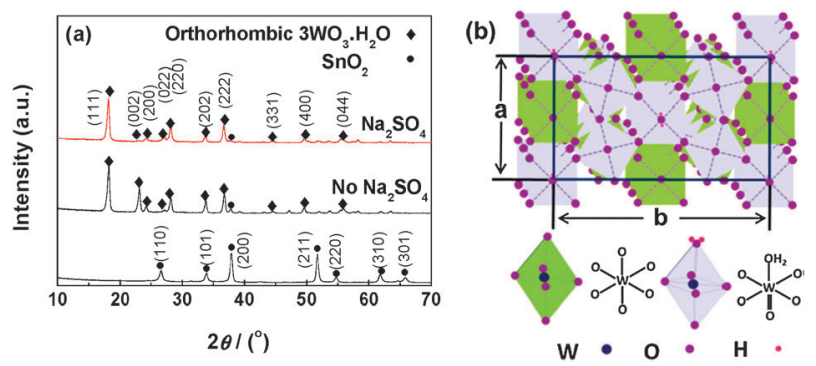

Fig. 1 (a) XRD patterns of the bare FTO substrate and, the assynthesized films grown with and without $\mathrm{Na}_{2} \mathrm{SO}_{4}$. (b) Schematic illustration of the $3 \mathrm{WO}_{3} \cdot \mathrm{H}_{2} \mathrm{O}$ structure. 
$3 \mathrm{WO}_{3} \cdot \mathrm{H}_{2} \mathrm{O}$ (JCPDF 87-1203). However, the relative peak intensity for crystalline planes of (002) and (200) of the film grown with $\mathrm{Na}_{2} \mathrm{SO}_{4}$ is different from the one without $\mathrm{Na}_{2} \mathrm{SO}_{4}$, indicating different preferred growing direction due to the capping effect of $\mathrm{Na}_{2} \mathrm{SO}_{4}$. The orthorhombic $3 \mathrm{WO}_{3} \cdot \mathrm{H}_{2} \mathrm{O}$ contains two types of corner-sharing $\mathrm{WO}_{6}$ octahedrons. One type is conducted by a central tungsten atom that is surrounded by six oxygen atoms, while in the second type, two of the oxygen atoms are replaced by a shorter terminal $\mathrm{W}=\mathrm{O}$ bond and a longer $\mathrm{W}-(\mathrm{OH})_{2}$ bond, respectively. ${ }^{22}$ The relatively weaker interaction between adjacent layers may restrict the stacking to prevent the bulk formation. Finally, the two dimensional plate-like $3 \mathrm{WO}_{3} \cdot \mathrm{H}_{2} \mathrm{O}$ nanostructure is formed under the capping effect of $\mathrm{Na}_{2} \mathrm{SO}_{4}$ by stacking up layers consisting of these two structural units as shown in Fig. 1b. The Raman spectrum and wide scanning X-ray photoelectron spectroscopy (XPS) of the nanoplate film were also investigated and shown in Fig. S1 and S2, ESI†, indicating that the as-prepared films are orthorhombic $3 \mathrm{WO}_{3} \cdot \mathrm{H}_{2} \mathrm{O}$ with high purity.

The morphologies of the as-synthesized films are shown in Fig. 2. The film grown with $\mathrm{Na}_{2} \mathrm{SO}_{4}$ is composed of plate-like nanostructures, forming a rough surface (Fig. 2a and b). These uniform nanoplates grow nearly vertically on the substrate. Numerous pores are formed among them so that the contact area between the film and electrolyte can be largely increased. Through these pores, ions in the electrolyte can diffuse more easily and efficiently. The cross-sectional view image (inset of Fig. 2b) shows that the film of $\sim 700 \mathrm{~nm}$ in thickness has a good adhesion to the substrate. Fig. 2c shows the transmission electron microscopy (TEM) image of the nanoplates. The biggest "rectangular block" with a size of $\sim 200 \mathrm{~nm}$ has vertical joint angles. The insets of Fig. $2 \mathrm{c}$ depict the selected area electron diffraction (SAED) pattern and high-resolution TEM (HRTEM) image of this nanoplate. Regular diffraction spots indicate that it is single crystalline with preferential growing directions along crystal planes of (200) and (002). The high-resolution TEM (HRTEM) image from the edge of a

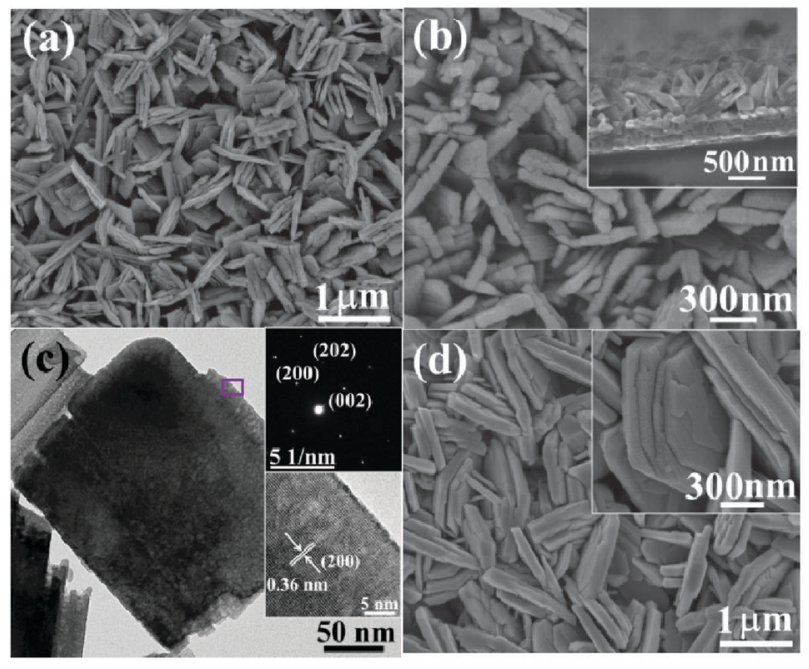

Fig. 2 (a) and (b) FESEM images of the $3 \mathrm{WO}_{3} \cdot \mathrm{H}_{2} \mathrm{O}$ thin films grown with $\mathrm{Na}_{2} \mathrm{SO}_{4}$ given under different magnifications. Inset of (b): crosssectional view image. (c) TEM image of the nanoplate scratched from the film. Inset: SAED pattern and HRTEM image. (d) FESEM images of the $3 \mathrm{WO}_{3} \cdot \mathrm{H}_{2} \mathrm{O}$ thin films grown without $\mathrm{Na}_{2} \mathrm{SO}_{4}$. Inset: larger magnification. single nanoplate shows a crystal lattice of $0.36 \mathrm{~nm}$, corresponding to the $d$-spacing of (200) planes. Clear lattice fringes also support its single crystal quality. Fig. $2 d$ presents a top view image of the film grown without $\mathrm{Na}_{2} \mathrm{SO}_{4}$. The inset shows the larger magnification image. The film is composed of stacking brick-like nanostructures with much bigger sizes. The surface area of the brick-like film is much smaller compared to the plate-like one. Consistent with the SEM studies, the mass density of the nanoplate film has been found to be approximately $3.2 \mathrm{~g} \mathrm{~cm}^{-3}$, estimated from mass and thickness data. Since the bulk density of orthorhombic $3 \mathrm{WO}_{3} \cdot \mathrm{H}_{2} \mathrm{O}$ is $6.6 \mathrm{~g} \mathrm{~cm}^{-3}$, the pore volume of the film was calculated to be $0.16 \mathrm{~cm}^{3} \mathrm{~g}^{-1}$, which is slightly smaller than the nanoparticle films. ${ }^{8}$ On the other hand, the mass density of the brick-like film grown without $\mathrm{Na}_{2} \mathrm{SO}_{4}$ is $5.4 \mathrm{~g} \mathrm{~cm}^{-3}$, yields a pore volume of $0.03 \mathrm{~cm}^{3} \mathrm{~g}^{-1}$, which is much smaller than the nanoplate film. The formation process of platelike and stacked brick-like $3 \mathrm{WO}_{3} \cdot \mathrm{H}_{2} \mathrm{O}$ films is schematically illustrated in Fig. S3 (ESI $\dagger$ ).

The cyclic voltammograms (CVs) normalized to the geometric area of the electrode and to the weight of film within that area are compared in Fig. 3a, measured in $0.5 \mathrm{M} \mathrm{H}_{2} \mathrm{SO}_{4}$ with a scan rate of $0.1 \mathrm{~V} \mathrm{~s}^{-1}$. During each scan, both films will reversibly change their colors from colorless to blue, resulting from $\mathrm{H}^{+}$intercalation/ deintercalation and electron transfer between $\mathrm{W}^{6+}$ and $\mathrm{W}^{5+}$ according to the following reaction:

$$
\begin{gathered}
\mathrm{WO}_{3} \cdot 0.33 \mathrm{H}_{2} \mathrm{O} \text { (bleach) }+x \mathrm{H}^{+}+x \mathrm{e}^{-} \\
\leftrightarrow \mathrm{H}_{x} \mathrm{WO}_{3} \cdot 0.33 \mathrm{H}_{2} \mathrm{O} \text { (blue). }
\end{gathered}
$$

The integrated cathodic/anodic current over time equates to the amount of $\mathrm{H}^{+}$intercalation/deintercalation. The nanoplate film leads to a much higher current density for both intercalation deintercalation processes over the same time period than the nanobrick one, indicating a faster $\mathrm{H}^{+}$intercalation/deintercalation kinetics. The total cathodic charge for the nanoplate film was about $0.67 \mathrm{mC} \mathrm{cm}^{-2} \mathrm{mg}^{-1}$, compared to only about $0.19 \mathrm{mC} \mathrm{cm}^{-2} \mathrm{mg}^{-1}$ for the nanobrick one. Moreover, the onset of the cathodic current for the nanoplate $(0.27 \mathrm{~V})$ is more positive compared with the nanobrick one $(0.15 \mathrm{~V})$, while the oxidation peak of the nanoplate film $(-0.17 \mathrm{~V})$ shows a negative shift compared to the nanobrick one $(-0.03 \mathrm{~V})$. These results imply that the nanoplate film has reduced interfacial charge-transfer resistance, providing another reason for the improved electrochemical response. The faster ion intercalation/deintercalation kinetics of the nanoplate film was further confirmed by the chronoamperometry result (Fig. 3b). The chronoamperometry test was conducted by applying a pulsed potential of $\pm 0.3 \mathrm{~V}$ for $30 \mathrm{~s}$ in each state. The nanoplate film
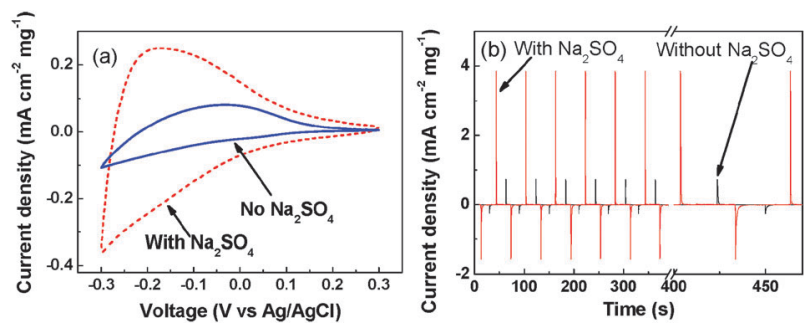

Fig. 3 (a) $\mathrm{CV}$ curves of the $3 \mathrm{WO}_{3} \cdot \mathrm{H}_{2} \mathrm{O}$ films grown without and with $\mathrm{Na}_{2} \mathrm{SO}_{4}$ in $0.5 \mathrm{M} \mathrm{H}_{2} \mathrm{SO}_{4}$ solution, at a scan rate of $0.1 \mathrm{~V} \mathrm{~s}^{-1}$. (b) Chronoamperometry curves by applying a pulsed potential of $\pm 0.3 \mathrm{~V}$, $30 \mathrm{~s}$ for each state. 

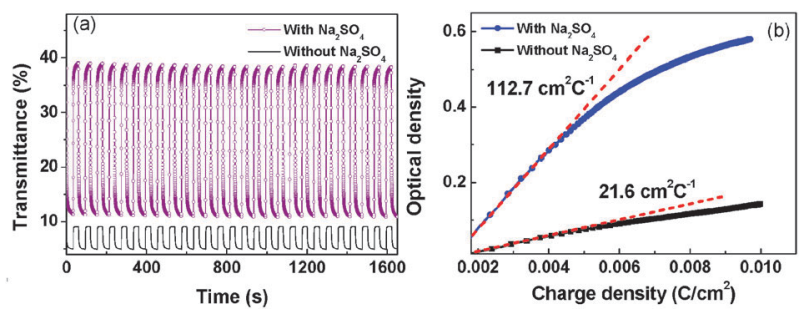

Fig. 4 (a) Switching time characteristics for both films measured at $\pm 0.3 \mathrm{~V}$ at $632.8 \mathrm{~nm}$. (b) Optical density variation with respect to the charge density recorded at $632.8 \mathrm{~nm}$.

reaches a higher transient current peak density and exhibits faster current decays than the nanobrick one, agreeing well with Fig. 3a. Moreover, the nanoplate film also shows good cyclic stability (Fig. S4a, ESI $\dagger$ ) even in the acidic solution, since there is no significant change in the shape of the CVs, only a small reduction was observed after 3000 cycles. On the other hand, a larger current reduction was observed for the nanobrick film (Fig. S4b, ESI $\dagger$ ), indicating an inferior stability. Tunable transmittance could be obtained for the nanoplate film under $-0.1,-0.2$ and $-0.3 \mathrm{~V}$ in $0.5 \mathrm{M} \mathrm{H}_{2} \mathrm{SO}_{4}$ solution (Fig. S5, ESI $\dagger$ ). Photographs of the EC device made of the plate-like film are shown in Fig. S6 (ESI $\dagger$ ), depicting a high contrast between the bleached and colored states which leads to the obvious transparency changes.

Fig. 4a shows the in situ coloration/bleaching transmittance response of the nanoplate and nanobrick films measured at $632.8 \mathrm{~nm}$. Obvious color changes can be observed during the switching. The nanoplate film shows a fast response and the switching time extracted for a $90 \%$ transmittance change are found to be $4.3 \mathrm{~s}$ for coloration $\left(t_{\mathrm{c}}\right)$ and $1.4 \mathrm{~s}$ for bleaching $\left(t_{\mathrm{b}}\right)$. However, for the nanobrick film, $t_{\mathrm{c}}$ and $t_{\mathrm{b}}$ are increased to 9.2 and $1.7 \mathrm{~s}$, respectively. Moreover, the film grown with $\mathrm{Na}_{2} \mathrm{SO}_{4}$ depicts an enhanced optical modulation of $38 \%$, which is larger than $5 \%$ of the nanobrick one. The fast coloration/ bleaching kinetics are mainly attributed to the small mass density and large surface area of the porous morphology, which facilitates the ions intercalation/deintercalation by reducing their diffusion path lengths. The switching speed of the film for both the coloration and bleaching is faster than previously reported micro-brick films and nanowire array films. ${ }^{7,12}$ Moreover, the switching responses of the nanoplate film under $\pm 0.1 \mathrm{~V}$ and $\pm 0.2 \mathrm{~V}$ were also further investigated (see Fig. S7, ESI $\dagger$ ).

Coloration efficiency (CE), defined as the change in optical density $\left(\mathrm{OD}=\log \left(T_{\mathrm{c}} / T_{\mathrm{b}}\right.\right.$ or $\left.\left.T_{\mathrm{b}} / T_{\mathrm{c}}\right)\right)$ per unit of charge $(Q)$ inserted into (or extracted from) the films, was investigated and is shown in Fig. 4b. The optical density (OD) plots were recorded at $\lambda=632.8 \mathrm{~nm}$ versus the inserted charge density $(Q)$ under $-0.3 \mathrm{~V}$. The CE was extracted as the slope of the line fitted to the linear region of the curve. The calculated CE value of the nanoplate film is $112.7 \mathrm{~cm}^{2} \mathrm{C}^{-1}$, which is improved by about $422 \%$ compared with the nanobrick film $\left(\mathrm{CE}=21.6 \mathrm{~cm}^{2} \mathrm{C}^{-1}\right)$. The $\mathrm{CE}$ value is also largely increased compared with the reported ones of the micro-brick film and nanoparticle film. ${ }^{7,8}$ Moreover, the electrochromic characteristic parameters of $\mathrm{WO}_{3}$ films fabricated by various methods are summarized for comparison and shown in Table S1 (ESI $\dagger$ ). The hydrothermally grown nanoplate $\mathrm{WO}_{3}$ (hydrate) film herein depicts some improvement in either response time or coloration efficiency.

In summary, nanostructured $3 \mathrm{WO}_{3} \cdot \mathrm{H}_{2} \mathrm{O}$ films were assembled on a FTO glass substrate by an efficient and facile crystalseed-assisted hydrothermal method. A plate-like nanostructured film was synthesized with $\mathrm{Na}_{2} \mathrm{SO}_{4}$ as the capping agent. Compared with the one without adding $\mathrm{Na}_{2} \mathrm{SO}_{4}$, the nanoplate film showed significantly improved EC performance, thanks to a smaller mass density and larger surface area. Such $3 \mathrm{WO}_{3} \cdot \mathrm{H}_{2} \mathrm{O}$ films with improved EC behavior hold great promise for energy-efficient smart windows and large-area information displays.

The authors would like to thank the financial support from the Science and Engineering Research Council, Agency for Science, Technology and Research (A*STAR) of Singapore (project no. 0921010057 and 092151 0088), Singapore National Research Foundation (NRF-RF-2009-09 and NRFCRP-6-2010-2), and National Natural Science Foundation of China (NSFC) (project no. 61006037 and 61076015).

\section{Notes and references}

1 C. R. Granqvist, Nat. Mater., 2006, 5, 89.

2 S. H. Baeck, K. S. Choi, T. F. Jaramillo, G. D. Stucky and E. W. McFarland, Adv. Mater., 2003, 15, 1269.

3 W. Cheng, E. Baudrin, B. Dunn and J. I. Zink, J. Mater. Chem., 2001, 11, 92 .

4 S. K. Deb, Sol. Energy Mater. Sol. Cells, 2008, 92, 245.

5 C. G. Granqvist, Electrochim. Acta, 1999, 44, 3005.

6 C. G. Granqvist, Sol. Energy Mater. Sol. Cells, 2000, 60, 201.

7 Z. H. Jiao, X. W. Sun, J. M. Wang, L. Ke and H. V. Demir, J. Phys. D: Appl. Phys., 2010, 43, 285501.

8 S. H. Lee, R. Deshpande, P. A. Parilla, K. M. Jones, B. To, A. H. Mahan and A. C. Dillon, Adv. Mater., 2006, 18, 763.

9 G. A. Niklasson and C. G. Granqvist, J. Mater. Chem., 2007, 17, 127.

10 R. D. Rauh, Electrochim. Acta, 1999, 44, 3165.

11 J. Zhang, J. P. Tu, X. H. Xia, Y. Qiao and Y. Lu, Sol. Energy Mater. Sol. Cells, 2009, 93, 1840.

12 J. Zhang, J. P. Tu, X. H. Xia, X. L. Wang and C. D. Gu, J. Mater. Chem., 2011, 21, 5492.

13 J. Zhang, X. L. Wang, X. H. Xia, C. D. Gu, Z. J. Zhao and J. P. Tu, Electrochim. Acta, 2010, 55, 6953.

14 D. Ma, J. Jiang, J. Huang, D. Yang, P. Cai, L. Zhang and S. Huang, Chem. Commun., 2010, 46, 4556.

15 C. Cantalini, H. T. Sun, M. Faccio, M. Pelino, S. Santucci, L. Lozzi and M. Passacantando, Sens. Actuators, B, 1996, 31, 81

16 X. Zhang, X. Lu, Y. Shen, J. Han, L. Yuan, L. Gong, Z. Xu, X. Bai, M. Wei, Y. Tong, Y. Gao, J. Chen, J. Zhou and Z. L. Wang, Chem. Commun., 2011, 47, 5804.

17 B. D. Alexander, P. J. Kulesza, L. Rutkowska, R. Solarska and J. Augustynski, J. Mater. Chem., 2008, 18, 2298.

18 B. Cole, B. Marsen, E. Miller, Y. F. Yan, B. To, K. Jones and M. Al-Jassim, J. Phys. Chem. C, 2008, 112, 5213.

19 Z. H. Jiao, J. M. Wang, L. Ke, X. W. Sun and H. V. Demir, $A C S$ Appl. Mater. Interfaces, 2010, 3, 229.

20 C. G. Granqvist, G. A. Niklasson and A. Azens, Appl. Phys. A. Mater. Sci. Process., 2007, 89, 29.

21 J. M. Wang, E. Khoo, P. S. Lee and J. Ma, J. Phys. Chem. C, 2009, 113, 9655.

22 L. Zhou, J. Zou, M. Yu, P. Lu, J. Wei, Y. Qian, Y. Wang and C. Yu, Cryst. Growth Des., 2008, 8, 3993. 